\title{
The Dynamic of Self-Compassion Reviewed from the Characteristics of a Disease
}

\author{
Anifah $^{1}$, E S H Hutahaean ${ }^{2}$ \\ \{anifahsulaiman@gmail.com ${ }^{1}$, erik.saut@dsn.ubharajaya.ac.id ${ }^{2}$ \} \\ Faculty of Psychology, Bhayangkara Jakarta Raya University ${ }^{1,2}$
}

\begin{abstract}
Abs tract. The act of caring about oneself by treating it well unconditionally is known as self compassion. Many people take it for granted until they have to experience a suffering. This research aims to explore how the characteristics of a disease, of both the mild one and the severe one, can affect the level of someone's self-compassion. Total number of research subjects is 101 people, who suffer from mild and severe diseases. The method used in this research is the quantitative study, the data is then analyzed descriptively to categorize the diseases. It is then followed by the comparation, correlation, and reg re ssion tests. The result of descriptive analysis shows that self-compassion level in subjects with severe diseases is higher. The correlation test results show that dis ease categorization is positively as sociated with selfcompassion. This finding reveals that when the category of a subject's disease level up, self-compassion will improve. The regression test show that disease categorization affects self-compassion, there's indication that the characteristics of a subject's dis ease can be highly significant to their level of selfcompassion, es pecially with regard to their health. The worse the disease, the higher the level of selfcompassion.
\end{abstract}

Keywords: Self Compassion, Disease Characteristics, Patient

\section{Introduction}

Self-care in the form of healthy behavior in daily life may indicate one's level of self-compassion [1]. Self-compassion helps one deal with any negative experience in life [2], including when they fall ill, both physically and psychologically [3]. The same as compassion alone, self-compassion shall develop when one suffers from something, either physically or emotionally, hence the conclusion stating that a suffering is the antecedent of self-compassion [4]-[6]. When one falls ill, the desire to reduce the pain arises that they would start on treatments, and start avoiding the habits that can worsen the pain. People call several proactive follow-ups to lessen the suffering self-compassion [7].

In obese patients with musculoskeletal pain, self-compassion is evident as a negative predictor, suggesting that self-compassion is an important variable in explaining how a patient adapts to the pain [8]. The high level of self-compassion in patients with severe diseases affects negative psychological effects positively [9]. As observed in some cancer patients, self-compassion can help with postsurgery psychological stress [10], [11]. Other research emphasize that when a patient is in pain, accepting the pain is the key to reducing it. This strongly indicates the importance of self-compassion in patient to improve their well-being despite the pain [12]. 
A person will tend to ignore self-compassion until they suffer from something severe. For example, a smoker who has not suffered from a severe disease will just ignore the danger of smoking, to the point they will deny the fact that smoking causes many diseases and disorders [13]. This usually leads to them suffering from an incurable disease since it is already too severe to treat. Most of the time, actions taken to recover from the disease turn out unsuccessful. At this point, the only possible actions of self-compassion include accepting the pain, and doing anything to keep the pain from getting worse.

Self-compassion is crucial to raise people's awareness of healthy habits and behavior [14]. It is needed the most when people are still in a great physical condition, not when they have fallen ill. Self-compassion can be beneficial for patients to help them accept the pain which hopefully leads to less suffering, and can act as a mechanism to prevent diseases especially for people who are prone to severe diseases. Therefore it is important for one to have self-compassion. To explore the phenomenon of people only caring about their health once falling ill, this research will investigate the role of self-compassion and the characteristics of a disease.

\section{Methods}

The subjects in this study consist of 101 people, 87 men and 14 women. Subjects are people who have illness with a history of smoking, are living in the area of Bekasi, and are over 21 years. Subjects are selected based on randomly determined criteria. Before being used to retrieve data, the scale is first determined through several validation processes, both qualitative and quantitative. The scale used in this data collection process is a self-compassion scale, compiled based on the components proposed by Neff (2003). Researchers generate the indicators qualitatively, which are then derived again in the form of statement items, based on components that have been determined beforehand.

The next process is to conduct a quantitative test of the items that have been prepared using content analysis with the aikens $\mathrm{V}$ method. The items that pass are then tested on 31 subjects. Based on the result of the trial, the researchers then conduct a different power test to see the reliability and different power of the items that have been made. Items that are considered eligible are ones that have a different power index above 0.30 . These items are used in the process of retrieving research data.

The analysis in this study uses the descriptive technique. This is used to group the subjects, based on the characteristics of their disease, into mild category and severe category. This study also uses a comparation test to compare the mean of self-compassion based on the characteristics of the diseases. Correlation test is also employed in this study to discover the relationship between the two variables to find out whether they can be used to explain the aforementioned phenomenon. Regression test is the last one, and is used to explain the process of the phenomena.

\section{Result and Discussions}

Based on descriptive data obtained from the subjects, the researchers classify the various types of diseases into two groups: diseases with mild characteristics and diseases with severe characteristics. Included in the mild diseases are cough, vertigo, dizziness, etc. (not internal disease), while those included in the severe diseases are heart, lung, and cancer (internal medicine). Severe illness is classified as a serious disease [15]. This is conducted to see the difference in the level of selfcompassion in the mild diseases group and the severe disease group.

Table 1. Disease Characteristics and Mean of Self Compassion

\begin{tabular}{ccccc}
\hline Characteristic & Total & Percentage & Mean of Self Compassion & $\begin{array}{c}\text { Deviatio } \\
\text { Standard }\end{array}$ \\
\hline Mild & 20 & $19.8 \%$ & 82.70 & 14.309
\end{tabular}


The result show s that out of 101 subjects, $19.8 \%$ of them have a history of mild disease while the other $80.2 \%$ have a history of severe disease. Mean value of the group of subjects with a history of moderate disease is 82.70 while that of the group of subjects with a history of severe disease is 89.84 . Standard deviation value of the group of subjects with a history of moderate disease is 14.309 while that of the group of subjects with a history of severe disease is 10.841 . This indic ates the difference in the level of self-compassion in the mild disease group and severe disease group.

The subjects in the group of mild diseases tend to deny the causes of their pain, suggesting too little concern for personal health. In contrast, the subjects in the group of severe diseases, as a result of the severe pain that they feel, usually care more about themselves. They will try hard to avoid behaviors that can aggravate the pain, and will routinely attend treatment session. For example, smokers who are still actively smoking and feel mild pain, such as coughing, usually will not want to stop smoking. While smokers who have experienced severe pain, such as cancer, heart or lung, will totally stop smoking and have routine treatment session to reduce or eliminate the pain. When a person is seriously ill then his self-compassion increases, due to increased efforts to regulate his healthy behavior [16].

When one is not willing to treat themselves better, especially with regard to physical health, they must feel that they are healthy. Then, when they experience a severe illness, they will be more concerned with their health. Thus self-compassion and the characteristics of the diseases suffered by one can be used to explain why the phenomenon occurs, for self-care is proven to have a significant relationship with the characteristics of a disease suffered by one.

Table 2. Correlation and Regression

\begin{tabular}{cccc}
\hline & Correlation & $R^{2}$ & Constant \\
\hline $\begin{array}{c}\text { Self Compassion*Disease } \\
\text { Characteristics }\end{array}$ & 0.241 & 0.58 & 75.560 \\
\hline
\end{tabular}

The result of the correlation test shows that self-compassion and the characteristics of diseases suffered by a subject have a relationship, with a correlation value of 0.241 . This shows that selfcompassion and disease characteristics suffered by a subject in this study can be used to explain the aforementioned phenomenon. This is a positive relationship, meaning that the more severe the characteristics of the disease suffered by a subject, the higher their level of self-compassion, resulting in better treatment for themselves. One important component of self compassion is self kindness [17], which means treating ourselves with kindness. Kindness for oneself is shown in how they treat themselves when they fall ill, by avoiding behavior that can aggravate their pain and attend routine treatment session.

With regard to how the process of the relationship between self-compassion and the characteristics of the disease suffered by a subject, the regression test shows a significance value of 0.58 , suggesting that the significance of disease characteristics suffered by the subjects can affect the level of self compassion by $58 \%$. The significance of disease characteristics on self compassion shows a constant of 75.56. This indicates that each increase in one unit of disease characteristic will increase selfcompassion by 75.56. It can be concluded that one will be much more concerned about their health condition when the characteristics of the diseases turn more severe. Severe disease category in this study includes cancer, heart, and lung (internal medicine), while mild category includes cough, dizziness, and the like (not internal disease). This is in line with previous research claiming that selfcompassion will make one more adaptive to severe illness [15]. 


\section{Conclusion and suggestions}

Self compassion between the group of subjects with mild disease characteristics and the group of subjects with severe disease characteristics is significantly different. The group of subjects with severe disease characteristic s shows a higher level of self compassion compared to the group of subjects with mild disease characteristics. This suggests that the concern for personal health will increase in people who have severe diseases compared to people who suffer from mild diseases.

Characteristics of a subject's disease have a positive relationship with self-compassion, suggesting that when the characteristics of the disease level up, the self-compassion also increases. This shows that the characteristics of diseases and self-compassion can be used to explain the phenomenon discussed in this study.

Characteristic s of a subject's disease is also proven to have an effect on self-compassion by $58 \%$. Each increase of one unit of disease characteristics will be accompanied by an increase in self-compassion by 75.56 .

For further research, a cross sectional study of self compassion is needed, especially one that is related to the development of self compassion in patients, focusing on how self-compassion is experienced by a person recovering from a severe illness, and whether it will lessen or remain the same.

\section{References}

[1] F. M. Sirois, R. Kitner, and J. K. Hirsch, "Self Compass ion, Affect, and Health Behaviors," Heal. Psychol.,pp. 1-9, 2014.

[2] M. R. Leary, E. B. Tate, C. E. Adams, A. B. Allen, and J. Hancock, "Self-Compassion and Reactions to Unpleasant Self-RelevantEvents : The Self-Compassion and Reactions to Unpleasant Self-Relevant Events : The Implications of Treating Oneself Kindly," no. May 2014, 2007.

[3] K. D. Neff, S. S. Rude, and K. L. Kirkpatrick, "An examination of self-compassion in relation to positive psychological functioning and personality traits," vol. 41, pp. 908-916, 2007.

[4] C. Germer, "The MindfulPath To Self-Compassion.”The Guilford Press, New York, p. 82, 2009.

[5] K. Neff, "Self-Compassion : An Alternative Conceptualization of a Healthy Attitude Toward Oneself," SelfIdentity, vol.2, pp. 85-101, 2003.

[6] D. Reyes, "SelfCompassion : A Concept Analysis," J. Holist. Nurs., vol. 20, no. 10, pp. 1-9, 2011.

[7] K. Neff, SelfCompassion : Stop beating yourselfup and leave insecurity behind. London: Hodder and Stoughton Ltd, 2011.

[8] A. A. Wren et al., "Self-compassion in patients with persistent musculoskeletal pain: Relationship of self-compassion to adjustment to persistent pain," J. Pain Symptom Manage., vol. 43, no. 4, pp. 759770, 2012.

[9] F. Purdie and S. Morley, "Self-compassion, pain and breaking a social contract," 2015.

[10] A. Przezdziecki, K. A. Sherman, A. Baillie, A. Taylor, E. Foley, and K. Stalgis -Bilinski, "My changed body: Breast cancer, body image, dis tress and self-compassion," Psychooncology., vol. 22, no. 8, pp. 1872-1879, 2013.

[11] D. T. Gillanders, A. K. Sinclair, M. MacLean, and K. Jardine, "Illness cognitions, cognitive fusion, avoidance and self-compassion as predictors of distress and quality of life in a heterogeneous sample of adults, after cancer," J. Context. Behav. Sci., vol. 4, no. 4, pp.300-311, 2015.

[12] J. Costa and J.Pinto-Gouveia, "Acceptance of pain, self-compassion and psychopathology: Using the Chronic Pain Acceptance Questionnaire to identify patients' subgroups," Clin. Psychol. Psychother., vol. 18, no. 4, pp. 292-302, 2011.

[13] P. Peretti-Watel, J. Constance, P. Guilbert, A. Gautier, F. Beck, and J. P. Moatti, "Smoking too few cigarettes to be at risk? Smokers' perceptions of risk and risk denial, a French survey," Tob. Control, vol. 16, no. 5, pp. 351-356, 2007.

[14] M. L. Terry, M. R. Leary, and N. Carolina, "Self-Compassion, Self-Regulation, and Health," Self 
Identity, vol. 10, no. 3, pp. 352-362, 2011.

[15] J. M. Brion, M. R. Leary, and A. S. Drabkin, "Self-compas sion and reactions to serious illness: The case of HIV," J. Health Psychol., vol. 19, no. 2, pp. 218-229, 2014.

[16] D. D. Biber and R. Ellis, "The effect of self-compassion on the self-regulation of health behaviors: A systematic review," J. Health Psychol., 2017.

[17] K. Neff and K. A.Dahm, Self-Compassion: What it is, what it does, and how it relates to mindfulness. New York: Springer, 2015. 